\title{
Permanent Magnet Synchronous Machine Temperature Estimation using Low-Order Lumped-Parameter Thermal Network with Extended Iron Loss Model*
}

\author{
*An extension of a full paper submitted to the International Conference on Power Electronics, Machines and Drives (PEMD) 2020 \\ Emebet Gebeyehu Gedlu, Oliver Wallscheid and Joachim Böcker \\ Power Electronics and Electric Drives, Paderborn University, Paderborn, Germany \\ Email: ${ }^{1}$ gedlu@lea.uni-paderborn.de, ${ }^{2}$ wallscheid@lea.uni-paderborn.de, ${ }^{3}$ boeker@lea.uni-paderborn.de
}

\begin{abstract}
Since temperature rise in electric machines is mainly due to power losses during electro-mechanical power conversion, temperature estimation is highly attached to power loss modelling. In this contribution, an extended iron loss model is introduced with a direct identification methodology in the context of temperature estimation. The iron loss model is implemented as part of a fourth-order lumped-parameter thermal network (LPTN), which is parametrised using empirical measurements and global identification. Once parameters are identified using training data, the LPTN model is validated using three unseen profiles cross-validation. Satisfactory estimation is achieved with the average mean squared error of $2.1 \mathrm{~K}^{2}$ and the error bias close to zero.
\end{abstract}

Index Terms-lumped-parameter thermal network, system identification, iron loss, condition monitoring

\section{INTRODUCTION}

Permanent magnet synchronous machines (PMSMs) are preferred machines for automotive applications because of their high power and torque densities. However, they are particularly vulnerable to high temperature because of the thermal property of the PM material. The magnetic flux produced by the PM decreases with increasing temperature and very high temperature can even cause permanent demagnetization [1]. Similar to any machine constructed with insulation coated coils, high temperature can cause damage to the insulation varnish and eventually shortened the device's life-time. Hence, temperature monitoring is crucial to reserve the machine safe and long-lasting. Besides, knowing the operating temperature in real-time is important in the drive control system in order to tune the controller's temperature-dependent parameters accordingly.

It is possible to measure the temperature of stationary parts of the machine using contact-type temperature sensors. Yet, it requires slip-ring or brushes to read measurement data from a spinning rotor. Wireless telemetry methods are available but they are costly and affect the robustness of the machine in the case of highly utilized traction PMSM. Generally, direct temperature measurement is an infeasible solution for automotive application due to difficulties to maintain or replace the embedded temperature sensors in case of failure. Alternative machine-model based temperature estimation techniques are available with a general category of flux observer, invasive and lumped-parameter thermal network (LPTN) methods [2]. In the flux observer method, PM flux is estimated using flux observers and it is mapped to the corresponding temperature. The invasive method is carried out by injecting high-frequency signal (voltage or current) via an inverter and observing magnet temperature deviation reflected on the current response. The first drawback of both methods is, they are restricted estimating only the PM temperature. Second, both methods require real-time terminal voltage value which requires a precise model of both the machine and inverter. Temperature estimation using LPTN is another desirable method in which a heat transfer process inside electric machines streamlined into a simplified thermal equivalent circuit.

In a general context, the temperature rise in an electric machine is due to power losses during electro-mechanical power conversion. Winding and core losses are the most significant ones for LPTN application. Mechanical and windage losses are neglected since their contribution is relatively small for highly utilised traction motors. The core losses can be further divided into hysteresis and eddy current losses. For real-time drive application, winding losses can be calculated for a given winding resistance and measured current. Whereas, a usual approach to determine iron losses is measuring total power losses and subtracting winding losses. Hence, all errors in the determination of total and winding losses directly add up an error in the iron losses values.

Measuring total losses requires further measurement devices, though exact power meters are expensive and maybe not available. In addition, it demands extra effort and time to make measurements over large speed and load range. In spite of measurement resources, allocating the total core losses is a challenging task since it is difficult to measure the power loss distribution. Even with electromagnetic finite element analysis (FEA), only rough estimations are acquired. In [12] an analytical iron loss approach is introduced using a two-term 
iron loss equation to calculate the total iron losses and divide them among machine components using constant dividing parameters. However, constant hysteresis and eddy current coefficients are applicable only for purely alternating flux and it is important to consider the effect of rotational flux which depends on geometry and construction of considered volume unit.

The aim of this contribution is estimating important motor temperatures using a low-order LPTN model with an extended iron loss model. It also provides a direct identification methodology of this spatial loss model in the context of temperature estimation. Instead of total core losses, individual core losses are calculated for each dominant temperature node by adapting the two-term core loss density equation for electric drive application. Uncertain parameters are tuned in their possible searching space using particle swarm optimisation (PSO) to minimise the estimation error in comparison to empirical measurements. Once parameters are identified using training data, the LPTN model is cross-validated using unseen load profiles.

\section{A. Lumped-parameter thermal network (LPTN)}

An electric machine, which is a non-homogeneous thermal body, can be represented as a combination of temperature nodes connected via thermal resistances to each other and external thermodynamic conditions [3]. For LPTN model with $n$ temperature nodes, the $x^{t h}$ node can be modelled using (1). Where $C_{x}$ is the thermal capacity of the considered volume element, $P_{x}$ is the heat power generated and $R_{x y}$ is the thermal resistance between the considered node $x$ and the neighbouring nodes $y$ with their respective temperatures $\vartheta_{x}$ and $\vartheta_{y}$.

$$
C_{x} \frac{\partial \vartheta_{x}}{\partial t}=P_{x}+\sum_{\substack{y=1 \\ y \neq x}}^{n} \frac{\vartheta_{y}-\vartheta_{x}}{R_{x y}}
$$

According to [2], [4], [5] the LPTN model can be named white box, light-grey box or dark-grey box models depending on the number of nodes $n$ and prior knowledge of material and geometrical data of the machine. In a white box, the machine geometry is divided into fine meshes (very large $n$ ) and their temperature is predicted using heat transfer theory equations solely based on material and geometrical data. The light-grey box method follows the same approach of material and geometrical data-based heat transfer equations, yet the medium level of discretisation ( 5-15 nodes) enables this method some degree of parameter optimisation using empirical measurements. In the dark-grey box method, only the most dominant heat paths are modelled (2-5 nodes) with limited knowledge of system geometry and material data. Hence, any low-order LPTN model lays in the third category, where parameters are identified using experimental training. Although a higher level of discretisation is advantageous to estimate a hot-spot temperature of different components of the motor, it leads to a large differential equation system which is not feasible for real-time temperature prediction. Low and medium-order LPTN models are demonstrated as favourable methods of estimating the machine temperature for electric drive application in real-time [5]. A low-order LPTN model is parametrised by roughly calculating model parameters and optimise them using empirical measurements.

\section{B. Low-order LPTN model}

Besides the usual state-space representation in most of the literatures, a real-time temperature estimation using LPTN can be implemented as shown in Fig. 1. The time derivative term in (1) is now discretised using Euler forward method with sampling time $T_{s}$ and sampling index $k$. The thermal capacitance $C_{x}$ of each node is considered as an invariant parameter over different operating points of the machine for a given specific heat capacity $c_{x}$ and mass $m_{x}$. The power loss $P_{x}$ depends on the operating point of the machine, it is a function of speed and load conditions. The thermal resistance $R_{x y}$ can be divided into conductive and convective thermal resistances depending on whether the heat transfer is due to temperature difference between two nodes representing solid material or it involves a mass flow of fluid. Conductive thermal resistances are assumed as constant values while convective thermal resistances are modelled as a function of exogenous variables such as the motor speed or temperature of the fluid involved. The effect of radiation-based heat transfer is neglected as it has only a minor impact on the overall thermal motor behaviour [1]. In general, estimating temperature using a low-order LPTN model is mainly modelling thermal resistances and power losses as a function of machine parameters and measurement signals.

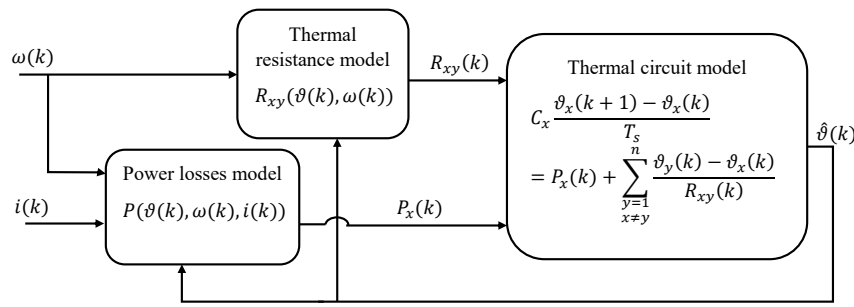

Fig. 1: General schematic of LPTN model for real-time temperature estimation. $\omega$ is angular speed of the machine, $i$ is measured current and $\hat{\vartheta}$ is estimated temperature.

A four-node $(n=4)$ LPTN model for a PMSM is proposed with dominant temperature nodes of stator winding $\vartheta_{S W}$, stator yoke $\vartheta_{S Y}$, stator tooth $\vartheta_{S T}$ and permanent magnet $\vartheta_{P M}$ as shown in Fig. 2. The coolant temperature $\vartheta_{C}$ is the temperature of water entering a stator cooling water jacket and $\vartheta_{A}$ is the ambient air temperature. One of the main reasons to choose these nodes is their availability to measure point temperature. Thermal resistances between nodes $\vartheta_{S W}$, $\vartheta_{S Y}$ and $\vartheta_{S T}$ are conductive thermal resistances which are modelled in white box modelling using (2). However, effective conduction length $l$, effective cross-section area $A$ and thermal conductivity $\lambda$ are not certain values. Hence, in low-order LPTN, thermal resistances $R_{S Y, S W}, R_{S Y, S T}$ and $R_{S W, S T}$ are 
generally considered as constant parameters whose values are to be disclosed using parameter identification.

A convective thermal resistance is commonly expressed by (3), such that $h$ is a non-linear heat transfer coefficient and $A$ is the contact surface area between the fluid and the solid bodies. However, $h$ is a function of fluid speed and temperature depending on whether the type of convective heat transfer is forced or natural one [7]. In [4], [5], this dependency is explained and consequently, the following convective thermal resistances are derived.

The thermal resistances connecting the water jacket with the stator yoke $R_{S Y, C}$ is given by (4). $R_{S Y, C, 0}$ is thermal resistance at the reference temperature $\vartheta_{C, 0}$ and $\alpha_{S Y, C}<0$ is temperature coefficient to represent temperature dependency of kinematic viscosity of the coolant. However, both $R_{S Y, C, 0}$ and $\alpha_{S Y, C}$ are not precisely known, so their values are subjected to parameter identification. It is also assumed that the water jacket is thermally in contact with the permanent magnet via bearing and shaft. Here, the thermal resistance depends both on the fluid temperature and speed of the shaft. Hence, the thermal resistance $R_{C, P M}$ is roughly formulated as (5), where $R_{x, C 0}, R_{x, C 1}, R_{x, C 2}$ and $R_{x, C 3}$ are part of the parameter identification. The heat transfer through airgap between stator and rotor is also a forced convective heat transfer which depends on rotor speed. Consequently, thermal resistances $R_{S T, P M}, R_{S W, P M}$ and $R_{P M, A}$ can be expressed using (6) [2], where $R_{x, y, 0}, b_{x, y}$ and $a_{x, y}$ are subjected to parameter identification.

$$
\begin{gathered}
R_{x, y}=\frac{l_{x}}{\lambda_{x} A_{x}}+\frac{l_{y}}{\lambda_{y} A_{y}} \\
R_{c o n v}=\frac{1}{h A} \\
R_{S Y, C}=R_{S Y, C, 0}\left[1+\alpha_{S Y, C}\left(\vartheta_{C}-\vartheta_{C, 0}\right)\right] \\
R_{P M, C}=R_{x, C 0}+R_{x, C 1}\left(\frac{n}{n_{\max }}\right)+R_{x, C 2}\left(\frac{\vartheta}{\vartheta_{\max }}\right) \\
+R_{x, C 3}\left(\frac{\vartheta}{\vartheta_{\max }}\right)\left(\frac{n}{n_{\max }}\right) \\
R_{x, y}=R_{x, y, 0} e^{-\frac{n}{n_{\max }} \frac{1}{b_{x, y}}}+a_{x, y}
\end{gathered}
$$

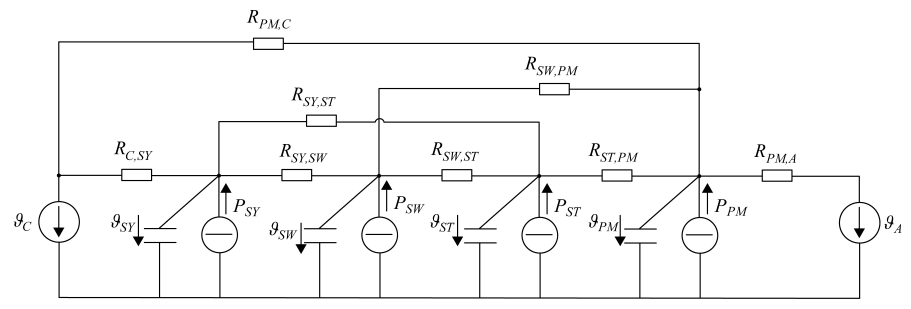

Fig. 2: Schematic of proposed LPTN model

\section{POWER LOSS MODEL}

In connection with the considered LPTN model, vital machine losses can be divided into winding losses and iron losses. Correspondingly, $P_{S W}$ is the winding loss and $P_{S T}, P_{S Y}$ and $P_{P M}$ are considered as iron losses. The winding loss is calculated using the winding resistance and the measured current using (7) considering temperature, skin and proximity effects [8]. Hence, the parameters $R_{d c}, \alpha_{C u}, \alpha_{a c, 1}, \alpha_{a c, 2}$ and $\beta_{C u}$ are unknown values to be determined using system identification.

$$
\begin{aligned}
P_{S W}= & 3 R_{d c}\left(\vartheta_{S W, 0}\right) I^{2}\left[\left(1+\alpha_{C u}\left(\vartheta_{S W}-\vartheta_{S W, 0}\right)\right)\right. \\
& \left.+\frac{\alpha_{a c, 1}\left(\frac{n}{n_{\max }}\right)+\alpha_{a c, 2}\left(\frac{n}{n_{\max }}\right)^{2}}{\left(1+\alpha_{C u}\left(\vartheta_{S W}-\vartheta_{S W, 0}\right)\right)^{\beta_{C u}}}\right]
\end{aligned}
$$

An extended iron loss model which is independent of the winding loss model is proposed as shown in Fig. 3. First, the iron loss at a fixed temperature $P_{i}\left(\vartheta_{0}, i, \omega\right)$ is calculated as a function of measured current and angular speed. Then, a linear temperature effect is formulated to attain $P_{\text {core }}(\vartheta, i, \omega)$ at any temperature $\vartheta$. A proposed iron loss model is based on a simplified two-term iron loss density equation (8), considering the first harmonic of flux density inside machine core, with frequency $f$ and peak value $B_{m}$. The coefficients $k_{h}\left(f, B_{m}, \vartheta\right)$ and $k_{e}\left(f, B_{m}, \vartheta\right)$ are the hysteresis loss and the eddy current loss coefficients respectively.

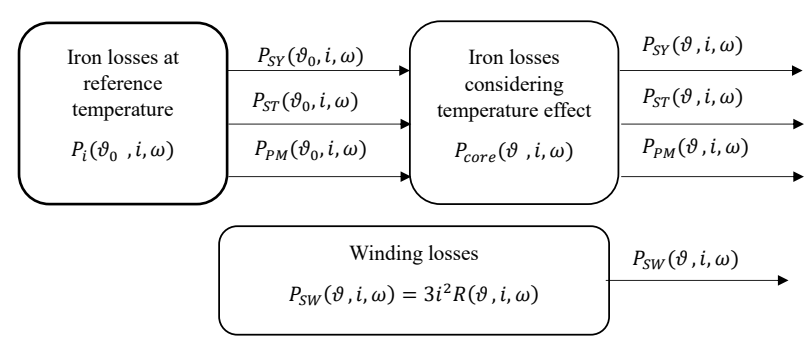

Fig. 3: Schematic of proposed extended iron loss model

Generally, (8) is only applicable for a small volume element of machine core material investigation (e.g. FEA). Hence, it needs adaptation for macroscopic application with the help of parameter identification. In case of PMSM, $f$ can be found from measured angular speed $\omega$ using (9), but $B_{m}$ inside the machine components cannot be simply defined. Hence, a rough estimate of the fundamental component of flux density using lumped parameters such as measured current is calculated. The first assumption is relating $B_{m}$ with maximum flux $\phi_{m}$ using (10), where $A$ is an effective area perpendicularly crossed by magnetic flux.

$$
\begin{gathered}
p_{F e}=k_{h}\left(f, B_{m}, \vartheta\right) f B_{m}^{2}+k_{e}\left(f, B_{m}, \vartheta\right) f^{2} B_{m}^{2} \\
f=\frac{\omega}{2 \pi} \\
B_{m}=\frac{\phi_{m}}{A}
\end{gathered}
$$


Then, the maximum flux can be calculated using the synchronous frame flux equation (11). Such that, $\phi_{d}$ is a d-axis flux as a function of d-axis current $i_{d}$ and PM flux, whereas $\phi_{q}$ is a q-axis flux as a function of q axis current $i_{q}$. Consequently, $B_{m}$ can split in to $d$ and $q$ component as shown (12) and (13). In the vein of magnetic saturation, flux density due to stator current is modelled using (14), where $m_{B, i}$ is a linear currentflux slope to be determined using parameter identification. The resulting flux-current relation of (14) is shown in Fig. 4 for different values of $m_{B, i}$. Whereas, the flux density due to permanent magnet $B_{P M}$ is part of the parameter identification.

$$
\begin{gathered}
\phi_{m}=\sqrt{\phi_{d}^{2}\left(i_{d}, \phi_{P M}\right)+\phi_{q}^{2}\left(i_{q}\right)} \\
B_{d}=B_{P M}+B\left(i_{d}\right) \\
B_{q}=B\left(i_{q}\right) \\
B(i)=m_{B, i}\left(\frac{i}{i_{\max }}\right) e^{-\frac{i}{i_{\max }}}
\end{gathered}
$$

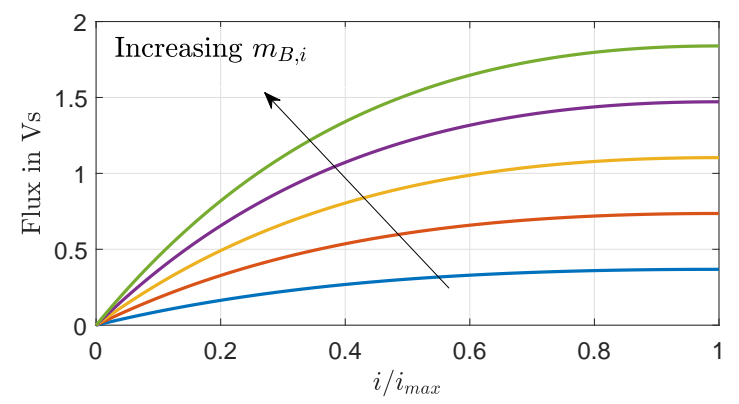

Fig. 4: Flux density due to stator current model considering core saturation

Both hysteresis and eddy current loss coefficients in (7) are not constant values in order to address excess losses and non-sinusoidal components of flux density. First, their dependency on $B_{m}$ is modelled using polynomial equations (15) and (16). Here, the polynomial coefficients $a_{h}$ and $a_{e}$ are not part of the parameter identification in order to minimise the number of parameters to be identified, since a large number of parameters can cause over-fitting. Instead, a curvefitting is made to Epstein measurement results in [9], [10] for different frequencies and machine core materials. Then, two separate average polynomial coefficients are derived for high frequency $\left(f_{h}=1000 \mathrm{~Hz}\right)$ and low frequency $\left(f_{l}=50 \mathrm{~Hz}\right)$ as shown in Tab. I. Then, the two polynomials are interpolated to the machine's range of frequencies using (17) which results variable coefficients $k_{h}\left(B_{m}\right)$ and $k_{e}\left(B_{m}\right)$ as shown in Fig. 5. Temperature dependency of both coefficients is formulated using (18), where $\alpha_{k}$ is a constant value to be identified using parameter identification. Since $p_{F e}$ is power loss mass density, the actual iron losses in the considered volume unit is given by (19), where $m$ is one of the parameters to be identified.

$$
k_{h}\left(B_{m}\right)=a_{h 0}+a_{h 1} B_{m}+a_{h 2} B_{m}^{2}
$$

$$
\begin{gathered}
k_{e}\left(B_{m}\right)=a_{e 0}+a_{e 1} B_{m}+a_{e 2} B_{m}^{2}+\ldots+a_{e 5} B_{m}^{5} \\
k\left(f, B_{m}\right)=\frac{f}{f_{\max }} k\left(f_{h}, B_{m}\right)+\left(1-\frac{f}{f_{\max }}\right) k\left(f_{l}, B_{m}\right) \\
k_{\vartheta}=k_{\vartheta_{0}}\left(1+\alpha_{k}\left(\vartheta-\vartheta_{0}\right)\right) \\
P_{F e}=m p_{F e}
\end{gathered}
$$
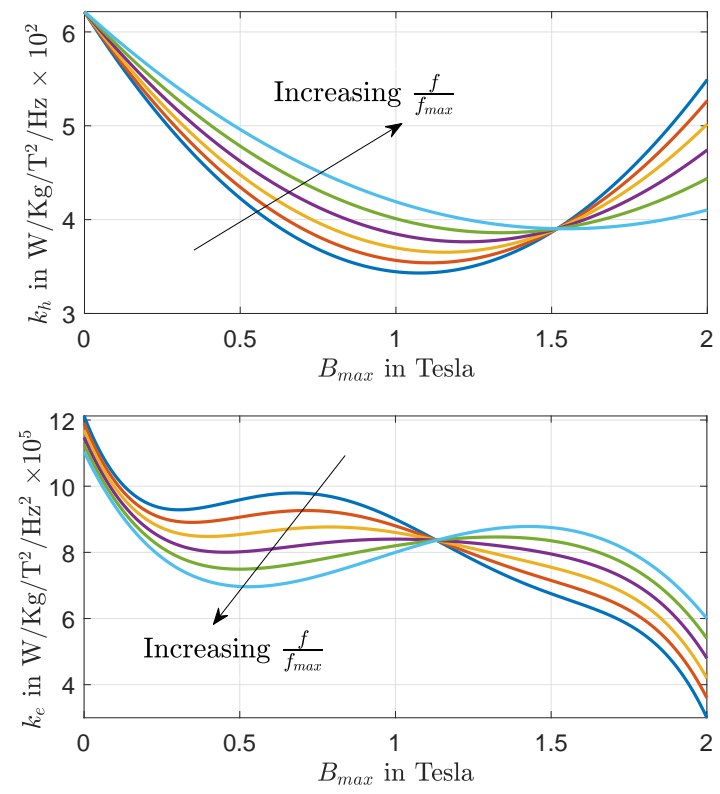

Fig. 5: $k_{h}\left(f, B_{m}, \vartheta_{0}\right), k_{e}\left(f, B_{m}, \vartheta_{0}\right)$ adaptation for extended iron loss model.

\section{PARAMETER IDENTIFICATION}

A vector of uncertain parameters $\boldsymbol{p}$ is tuned in its possible searching space vector using particle swarm optimisation (PSO) to minimise a maximum likelihood cost function given by (20). The estimation error $\boldsymbol{e}(k, \boldsymbol{p})$ is a vector column of the four temperature nodes given as (21) and (22) sampling index $k$. Where, $\vartheta(k)$ is measured temperature and $\hat{\vartheta}(k, \boldsymbol{p})$ is estimated temperature. A global optimisation using PSO is preferred since the LPTN model discussed above is non-linear and parameter varying which may cause convergence to the local minimum for other gradient based optimisations.

$$
\begin{gathered}
J(\boldsymbol{p})=\operatorname{det}\left(\sum_{k=1}^{N} \boldsymbol{e}(k, \boldsymbol{p}) \boldsymbol{e}(k, \boldsymbol{p})^{T}\right) \\
\boldsymbol{e}(k, \boldsymbol{p})=\left[e_{S Y}(k, \boldsymbol{p}), e_{S W}(k, \boldsymbol{p}), e_{S T}(k, \boldsymbol{p}), e_{P M}(k, \boldsymbol{p})\right]^{T} \\
e(k, \boldsymbol{p})=\vartheta(k)-\hat{\vartheta}(k, \boldsymbol{p})
\end{gathered}
$$

The most important parameters in relation to the considered low-order LPTN model are defined with analytical formulation of a white box model in section II. This results in a total of 43 constant valued parameters as shown in Tab. II. Hence, the MATLAB global optimisation toolbox with a swarm of 430 particles is used to search the global minimum. Possible 
TABLE I: $k_{e}\left(B_{m}\right)$ and $k_{e}\left(B_{m}\right)$ polynomial coefficients for high frequency $\left(f_{h}=1000 \mathrm{~Hz}\right)$ and low frequency $\left(f_{l}=50 \mathrm{~Hz}\right)$

\begin{tabular}{|c|c|c|c|c|c|c|}
\hline $\begin{array}{l}\text { Polynomial } \\
\text { coefficients }\end{array}$ & $\begin{array}{l}a_{h 0} \text { in } \\
\mathrm{W} / \mathrm{kg} / \mathrm{T}^{2} / \mathrm{Hz}\end{array}$ & $\begin{array}{l}a_{h 1} \text { in } \\
\mathrm{W} / \mathrm{kg} / \mathrm{T}^{3} / \mathrm{Hz}\end{array}$ & $\begin{array}{l}a_{h 2} \text { in } \\
\mathrm{W} / \mathrm{kg} / \mathrm{T}^{4} / \mathrm{Hz}\end{array}$ & & & \\
\hline $\begin{array}{l}\text { Value at } f_{h} \\
\text { Value at } f_{l}\end{array}$ & $\begin{array}{l}2.40 \times 10^{-2} \\
4.62 \times 10^{-2}\end{array}$ & $\begin{array}{l}-5.17 \times 10^{-2} \\
-8.54 \times 10^{-2}\end{array}$ & $\begin{array}{l}6.21 \times 10^{-2} \\
6.21 \times 10^{-2}\end{array}$ & & & \\
\hline $\begin{array}{l}\text { Polynomial } \\
\text { coefficients }\end{array}$ & $\begin{array}{l}a_{e 0} \text { in } \\
\mathrm{W} / \mathrm{kg} / \mathrm{T}^{2} / \mathrm{Hz}^{2}\end{array}$ & $\begin{array}{l}a_{e 1} \text { in } \\
\mathrm{W} / \mathrm{kg} / \mathrm{T}^{3} / \mathrm{Hz}^{2}\end{array}$ & $\begin{array}{l}a_{e 2} \text { in } \\
\mathrm{W} / \mathrm{kg} / \mathrm{T}^{4} / \mathrm{Hz}^{2}\end{array}$ & $\begin{array}{l}a_{e 3} \text { in } \\
\mathrm{W} / \mathrm{kg} / \mathrm{T}^{5} / \mathrm{Hz}^{2}\end{array}$ & $\begin{array}{l}a_{e 4} \text { in } \\
\mathrm{W} / \mathrm{kg} / \mathrm{T}^{6} / \mathrm{Hz}^{2}\end{array}$ & $\begin{array}{l}a_{e 5} \text { in } \\
\mathrm{W} / \mathrm{kg} / \mathrm{T}^{7} / \mathrm{Hz}^{2}\end{array}$ \\
\hline $\begin{array}{l}\text { Value at } f_{h} \\
\text { Value at } f_{l}\end{array}$ & $\begin{array}{l}-8.79 \times 10^{-5} \\
-1.02 \times 10^{-5}\end{array}$ & $\begin{array}{l}46.46 \times 10^{-5} \\
6.54 \times 10^{-5}\end{array}$ & $\begin{array}{l}-89.27 \times 10^{-5} \\
-20.44 \times 10^{-5}\end{array}$ & $\begin{array}{l}72.97 \times 10^{-5} \\
31.34 \times 10^{-5}\end{array}$ & $\begin{array}{l}-24.49 \times 10^{-5} \\
-19.46 \times 10^{-5}\end{array}$ & $\begin{array}{l}12.12 \times 10^{-5} \\
11.04 \times 10^{-5}\end{array}$ \\
\hline
\end{tabular}

TABLE II: Identified parameters and their corresponding values

\begin{tabular}{|c|c|c|c|c|c|}
\hline & \multirow{5}{*}{$\begin{array}{l}\text { Variable } \\
C_{S Y} \\
C_{S T} \\
C_{S W} \\
C_{P M} \\
\end{array}$} & \multirow{5}{*}{$\begin{array}{l}\text { Identified Value } \\
6.838 \times 10^{3} \mathrm{~J} / \mathrm{K} \\
1.607 \times 10^{3} \mathrm{~J} / \mathrm{K} \\
3.589 \times 10^{3} \mathrm{~J} / \mathrm{K} \\
6.352 \times 10^{3} \mathrm{~J} / \mathrm{K}\end{array}$} & \multicolumn{2}{|c|}{ Searching Range } & \multirow[t]{5}{*}{ Remark } \\
\hline \multirow{4}{*}{$\begin{array}{l}\text { Thermal } \\
\text { capacitances } \\
\left(C_{x}\right)\end{array}$} & & & {$\left[3.70 \times 10^{3}\right.$} & $8.54 \times 10^{3} \mathrm{~J} / \mathrm{K}$ & \\
\hline & & & {$[356.82$} & $8.56 \times 10^{3} \mathrm{JJ} / \mathrm{K}$ & \\
\hline & & & {$[832.13$} & $7.49 \times 10^{3} \mathrm{JJ} / \mathrm{K}$ & \\
\hline & & & {$\left[1.28 \times 10^{3}\right.$} & $1.28 \times 10^{4} \mathrm{JJ} / \mathrm{K}$ & \\
\hline \multirow{3}{*}{$\begin{array}{l}\text { Conductive thermal } \\
\text { resistances }\end{array}$} & $R_{S Y, S T}$ & $0.0136 \mathrm{~K} / \mathrm{W}$ & {$[0.0051$} & $0.1428] \mathrm{K} / \mathrm{W}$ & \\
\hline & $R_{S Y, S W}$ & $0.216 \mathrm{~K} / \mathrm{W}$ & {$[0.0242$} & $0.579] \mathrm{K} / \mathrm{W}$ & \\
\hline & $R_{S W, S T}$ & $0.0158 \mathrm{~K} / \mathrm{W}$ & {$[0.0115$} & $0.3696] \mathrm{K} / \mathrm{W}$ & \\
\hline \multirow{15}{*}{$\begin{array}{l}\text { Convective thermal } \\
\text { resistances }\end{array}$} & $R_{S Y, C, 0}$ & $0.0168 \mathrm{~K} / \mathrm{W}$ & {$[0.012$} & $0.018] \mathrm{K} / \mathrm{W}$ & \\
\hline & $\alpha_{S Y, C}$ & $-0.0021 / \mathrm{K}$ & {$[-0.015$} & $0] 1 / \mathrm{K}$ & varrabies in $\kappa_{S Y, C}$ \\
\hline & $R_{P M, C 0}$ & $1.98 \mathrm{~K} / \mathrm{W}$ & {$[0$} & 2] K/W & \multirow{4}{*}{ variables in $R_{P M, C}$} \\
\hline & $R_{P M, C 1}$ & $0.99 \mathrm{~K} / \mathrm{W}$ & {$[-1.5$} & 1] K/W & \\
\hline & $R_{P M, C 2}$ & $0.99 \mathrm{~K} / \mathrm{W}$ & {$[-1.5$} & 1] $\mathrm{K} / \mathrm{W}$ & \\
\hline & $R_{P M, C 3}$ & $2.50 \mathrm{~K} / \mathrm{W}$ & {$[-3$} & 3] K/W & \\
\hline & $R_{P M, S T 0}$ & $6.97 \mathrm{~K} / \mathrm{W}$ & {$[0$} & 7] K/W & \multirow{3}{*}{ variables in $R_{P M, S T}$} \\
\hline & $b_{P M, S T}$ & 0.0413 & {$[0.001$} & 2] K/W & \\
\hline & $a_{P M, S T}$ & $0.565 \mathrm{~K} / \mathrm{W}$ & {$[0.001$} & 1] K/W & \\
\hline & $R_{P M, S W 0}$ & $0.804 \mathrm{~K} / \mathrm{W}$ & {$[0$} & 7] $\mathrm{K} / \mathrm{W}$ & \multirow{3}{*}{ variables in $R_{P M, S W}$} \\
\hline & $b_{P M, S W}$ & 0.261 & {$[0.001$} & $2.5]$ & \\
\hline & $a_{P M, S W}$ & $0.081 \mathrm{~K} / \mathrm{W}$ & {$[0.001$} & $1.5] \mathrm{K} / \mathrm{W}$ & \\
\hline & $R_{P M, A 0}$ & $0.863 \mathrm{~K} / \mathrm{W}$ & {$[0$} & 7] $\mathrm{K} / \mathrm{W}$ & \\
\hline & $b_{P M, A}$ & 0.19 & {$[0.001$} & & variables in $R_{P M, A}$ \\
\hline & $a_{P M, A}$ & $0.104 \mathrm{~K} / \mathrm{W}$ & {$[0.001$} & 1] K/W & \\
\hline \multirow{21}{*}{ Power losses } & $\alpha_{a c 1}$ & 0.617 & {$[0$} & $0.8]$ & \multirow{5}{*}{ variables in $P_{S W}$} \\
\hline & $\alpha_{a c 2}$ & 0.950 & {$[0$} & $0.95]$ & \\
\hline & $R_{S 0}$ & $0.016 \Omega$ & {$[0.01225$} & $0.017] \Omega$ & \\
\hline & $\beta_{C u}$ & 1.711 & {$[0.001$} & & \\
\hline & $\alpha_{C u}$ & $0.0011 / \mathrm{K}$ & {$[0$} & $0.0049 \mathrm{]} 1 / \mathrm{K}$ & \\
\hline & $m_{B, i, S T}$ & $0.603 \mathrm{~T}$ & {$[0.6000$} & $2.4000] \mathrm{T}$ & \multirow{5}{*}{ variables in $P_{S T}$} \\
\hline & $B_{P M, S T}$ & $0.908 \mathrm{~T}$ & {$[0.6000$} & $1.2000] \mathrm{T}$ & \\
\hline & $m_{S T}$ & $2.589 \mathrm{Kg}$ & {$[2$} & 5] $\mathrm{Kg}$ & \\
\hline & $\alpha_{k h, S T}$ & $0.0121 / \mathrm{K}$ & {$[-0.12$} & $0.12]$ & \\
\hline & $\alpha_{k e, S T}$ & $-0.01851 / \mathrm{K}$ & {$[-0.12$} & $0.12]$ & \\
\hline & $m_{B, i, S Y}$ & $2.372 \mathrm{~T}$ & {$[0.6000$} & $2.4000] \mathrm{T}$ & \multirow{5}{*}{ variables in $P_{S Y}$} \\
\hline & $B_{P M, S Y}$ & $1.104 \mathrm{~T}$ & {$[0.6000$} & $1.2000] \mathrm{T}$ & \\
\hline & $m_{S Y}$ & $2.29 \mathrm{Kg}$ & {$[2$} & 5] $\mathrm{Kg}$ & \\
\hline & $\alpha_{k h, S Y}$ & $-0.1191 / \mathrm{K}$ & {$[-0.12$} & $0.12] 1 / \mathrm{K}$ & \\
\hline & $\alpha_{k e, S Y}$ & $-0.1171 / \mathrm{K}$ & {$[-0.12$} & $0.12] 1 / \mathrm{K}$ & \\
\hline & $m_{B_{d}, i, S T}$ & $0.603 \mathrm{~T}$ & {$[0.6000$} & $2.4000] \mathrm{T}$ & \multirow{6}{*}{ variables in $P_{S Y}$} \\
\hline & $m_{B_{q}, i, S T}$ & $2.4000 \mathrm{~T}$ & {$[0.6000$} & $2.4000] \mathrm{T}$ & \\
\hline & $m_{P M}$ & $2.06 \mathrm{Kg}$ & {$[2$} & 5] $\mathrm{Kg}$ & \\
\hline & $B_{P M, P M}$ & $1.2000 \mathrm{~T}$ & {$[0.6000$} & $1.2000] \mathrm{T}$ & \\
\hline & $\alpha_{k h, P M}$ & $-0.02591 / \mathrm{K}$ & {$[-0.12$} & $0.12] 1 / \mathrm{K}$ & \\
\hline & $\alpha_{k e, P M}$ & $0.0051 / \mathrm{K}$ & {$[-0.12$} & $0.12] 1 / \mathrm{K}$ & \\
\hline
\end{tabular}


searching interval boundaries are defined using rough estimation of a white box model, see Tab. II. Moreover, the MATLAB PSO is combined with fmincon as a hybrid function if in case the PSO give up earlier than finding the global optimum, gradient-based optimisation will take over.

Regarding experimental data sets, 140 hours measurement data are collected considering all possible and relevant operating points of the machine with sampling time $0.5 \mathrm{~s}$. The data set is available in a mildly normalised form at [13]. Most of the data sets are used as a training data set in the PSO process while three of them are reserved for cross-validation. A time series of scheduling parameters such as speed, current and water and ambient air temperatures from the training data set are applied to the LPTN model to retrieve parameters which minimise the cost function $J$. The optimization took $48 \mathrm{hr}$ using parpool MATLAB toolbox and 172 computing nodes of Paderborn university's parallel computing centre $\mathrm{PC}^{2}$. The identified parameters and their corresponding values are given in Tab. II.

\section{CROSS-VALIDATION}

Once parameters are identified using the training data set, the LPTN model is validated using unseen profile crossvalidation. For this purpose, three data profiles with dynamic speed and loading conditions are chosen as shown in Fig. 6, 8 and 10. A large speed range from zero to the machine's maximum speed with different accelerations and decelerations is covered. In the meanwhile, the load torque is incorporated in both motoring and generating modes from no load to maximum rated torque.

In the same figure, estimated and measured temperatures of the four temperature nodes are compared for the given speed and load profiles. The estimation error time series show satisfactory estimation is achieved with the worst temperature error of less than $9{ }^{\circ} \mathrm{C}$. The estimation error bias for the three temperature nodes $\vartheta_{S Y}, \vartheta_{S W}$ and $\vartheta_{S T}$ are close to zero as shown in the error histogram of Fig. 7, 9 and 11. Yet, the error bias of $\vartheta_{P M}$ indicates there is still a room for the LPTN model improvement.

\section{Conclusion}

An extended iron loss model is presented as part of loworder LPTN for PMSM temperature estimation by adapting the two-term iron loss density equation. A hysteresis and eddy current losses which are a function of magnetic flux density and frequency are formulated as a function of measured current and speed with the help of system identification. The estimation performance is tested with different unseen profiles cross validation. Acceptable temperature estimation is achieved with the average mean squared error of $2.1 \mathrm{~K}^{2}$ and the error bias close to zero, aside from measuring total power loss and storing it in lookup table as part of the estimator model.

This avoids expensive power loss measurement devices and the time and effort to measure total power loss over large operating points of the machine. Furthermore, it provides a direction to real-time iron loss estimation using measured current and angular speed in relation to temperature estimation application. Compared to the gold standard of achieving Gaussian distributed white noise estimation error with minimum variance, further investigation on the extended loss model in addition to passive parameters identification of the LPTN models is rewarding since the overall optimal model topology seems been not found yet.

\section{REFERENCES \\ REFERENCES}

[1] Wang, A., Li, H., Liu C-T., "On the material and temperature impacts of interior permanent magnet machine for electric vehicle applications." IEEE Transactions on Magnetics, 2008 11, pp. 4329-4332.

[2] Wallscheid, O., Huber, T., Peters, W., et al. "A critical review of techniques to determine the magnet temperature of permanent magnet synchronous motors under real-time conditions." EPE Journal, 20161 (26), pp. 11-20.

[3] Mellor, P. H., D. Roberts, D. R. Turner "Lumped-parameter thermal model for electrical machines of TEFC design.” IEE Proceedings B Electric Power Applications, 1991 09, pp. 205-218.

[4] Wallscheid, O., Böcker, J. "Design and identification of a lumpedparameter thermal network for permanent magnet synchronous motors based on heat transfer theory and particle swarm optimisation.", 17th European Conference on Power Electronics and Applications (EPE'15 ECCE-Europe), Geneva, Switzerland, Sept 2015, pp. 1-10

[5] Wallscheid, O., Böcker, J. "Global identification of a low-order lumpedparameter thermal network for permanent magnet synchronous motors.' IEEE Transactions on Energy Conversion, 201509 (24), pp. 354-365.

[6] Huber, T., Peters, W., Böcker, J. "Monitoring critical temperatures in permanent magnet synchronous motors using low-order thermal models." 2014 International Power Electronics Conference (IPEC-Hiroshima 2014 - ECCE ASIA), Hiroshima, Japan, May 2014, pp. 1508-1515

[7] Staton, D. A., Cavagnino, A.'Convection heat transfer and flow calculations suitable for electric machines thermal models." IEEE transactions on industrial electronics, 200809 (30), 55, pp. 3509-3516.

[8] Wrobel, R., Salt, D. E., Griffo, A., et al. "Derivation and scaling of AC copper loss in thermal modeling of electrical machines." IEEE Transactions on Industrial Electronics 61, no. 8 (2013): 4412-4420.

[9] Ionel, D. M., Popescu, M., McGilp, M. I., et al. "Computation of core losses in electrical machines using improved models for laminated steel." IEEE Transactions on Industry Applications, 200712 (19), pp. 15541564.

[10] Xue, S., Feng, J., Guo, S., et al. "A new iron loss model for temperature dependencies of hysteresis and eddy current losses in electrical machines.” IEEE Transactions on Magnetics, 201712 (06), pp. 1-10.

[11] Sun, Le., Dhale, S., Nalakath, S., et al. "Non-Linear OptimisationBased Temperature Estimation of IPMSM.” In 2019 IEEE Transportation Electrification Conference and Expo (ITEC), Detroit, MI, USA, USA, June 2019, pp. 1-7.

[12] Boglietti, A., Cavagnino, A., Lazzari, M., et al. "Predicting iron losses in soft magnetic materials with arbitrary voltage supply: An engineering approach.” IEEE Transactions on Magnetics, 200304 (02), pp. 981-989.

[13] 'Electric Motor Temperature, $140 \mathrm{hrs}$ recordings from a permanent magnet synchronous motor (PMSM)' https://www.kaggle.com/wkirgsn/electric-motor-temperature, accessed 09 December 2019

[14] Gedlu, E.G., Wallscheid, O., Böcker, J. "Permanent magnet synchronous machine temperature estimation using low-order lumped-parameter thermal network with extended iron loss model (An extension of a full paper submitted to the International Conference on Power Electronics, Machines and Drives (PEMD 2020))", 

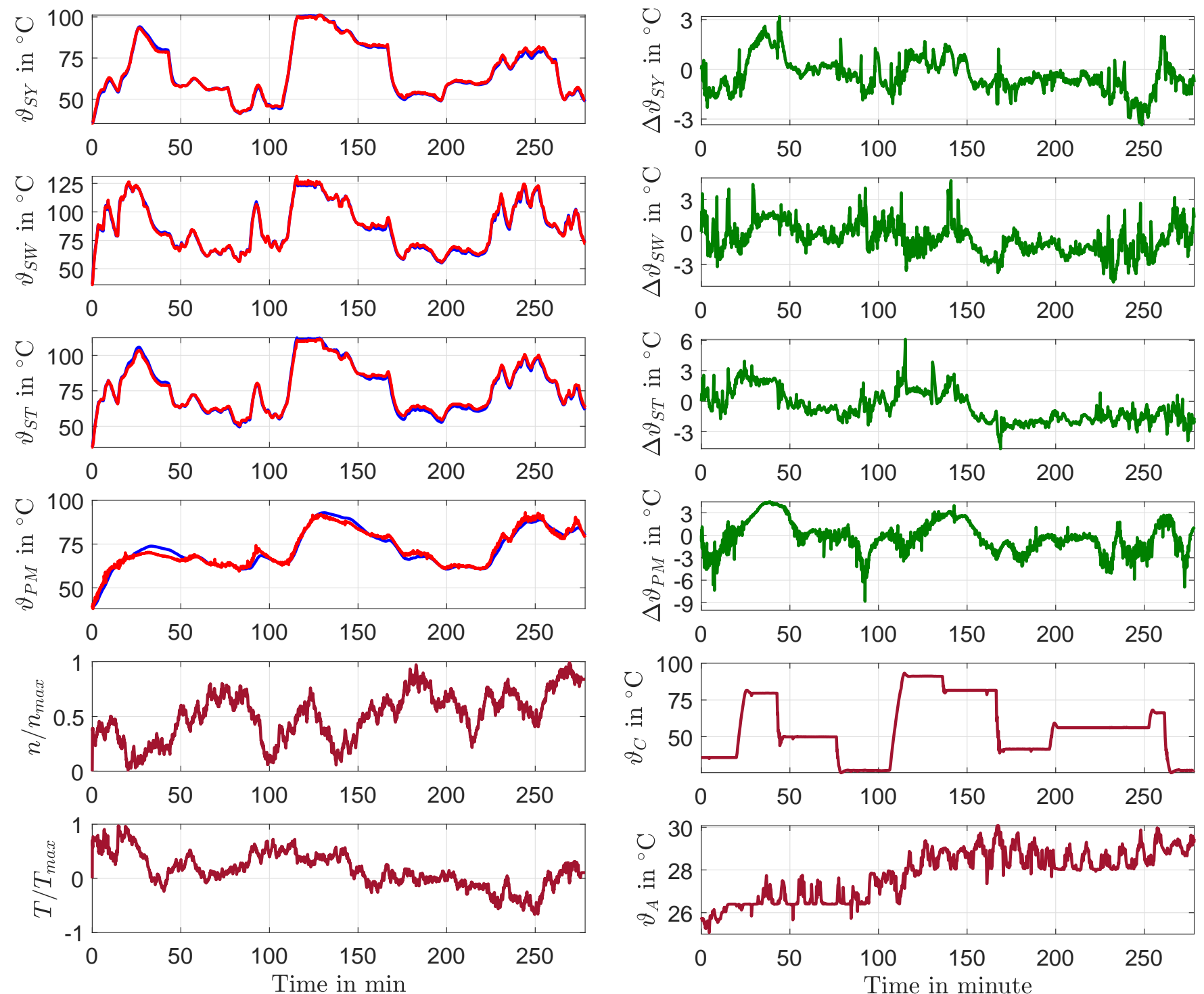

Fig. 6: LPTN validation with unseen profile. (—measured temperature,-estimated temperature, —error temperatures— unseen cross-validation profile), Profile 1
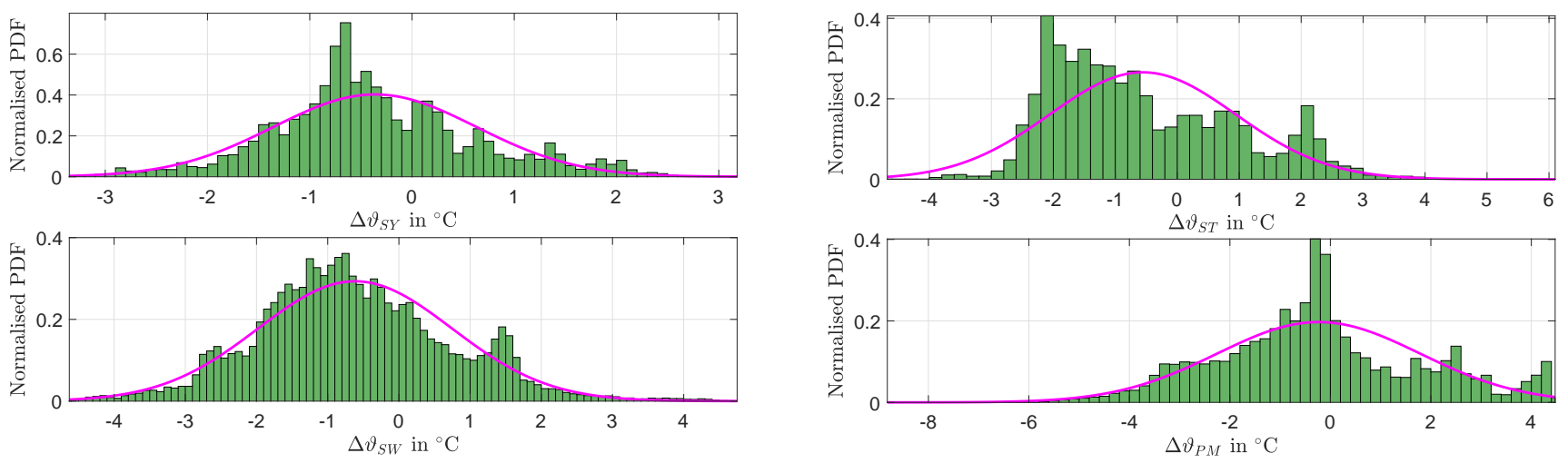

Fig. 7: Histogram of estimation error. (— Normalised probability density function (pdf), —Gaussian distribution), Profile 1 

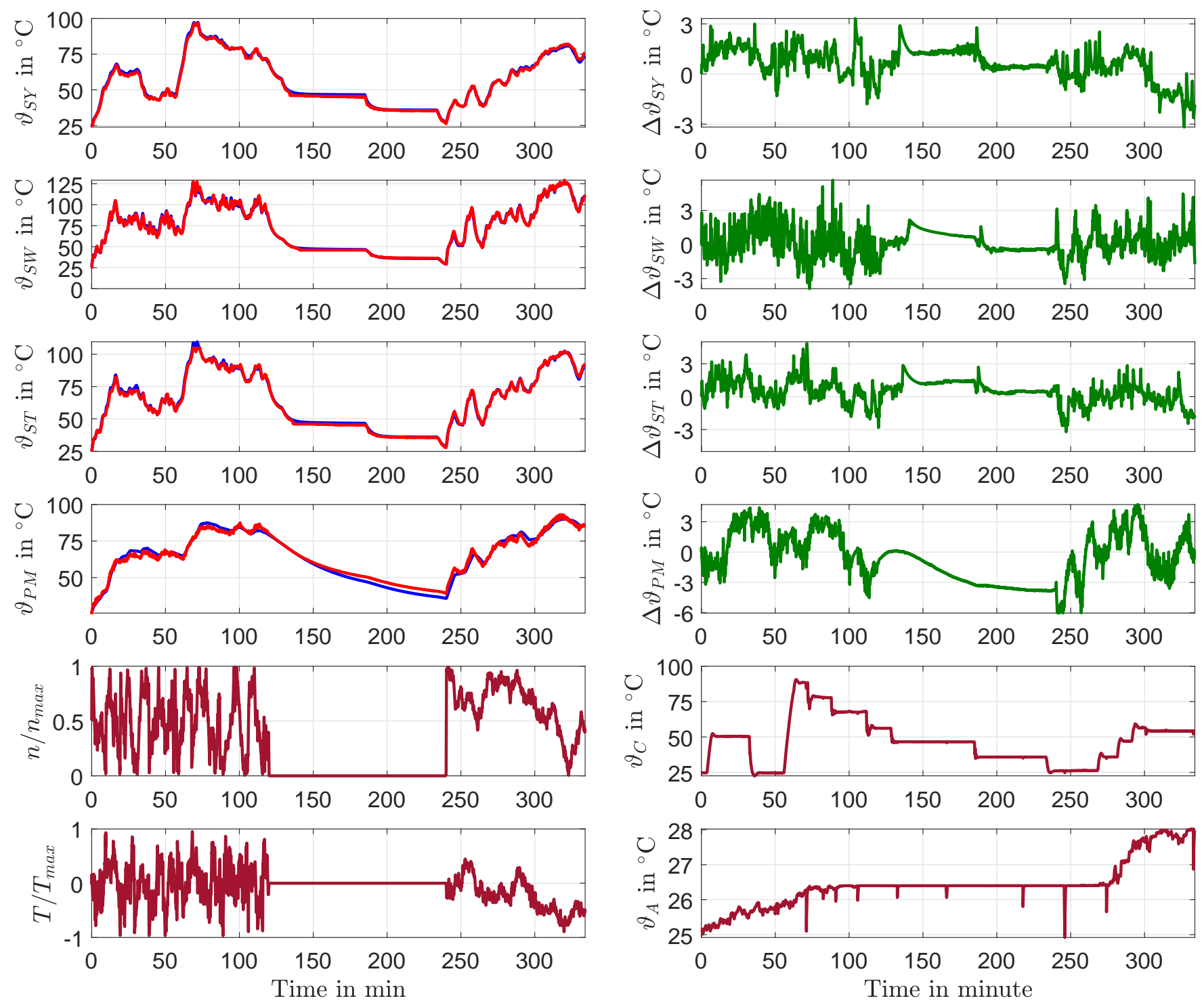

Fig. 8: LPTN validation with unseen profile. (—measured temperature,-estimated temperature,- - error temperatures- unseen cross-validation profile), Profile 2
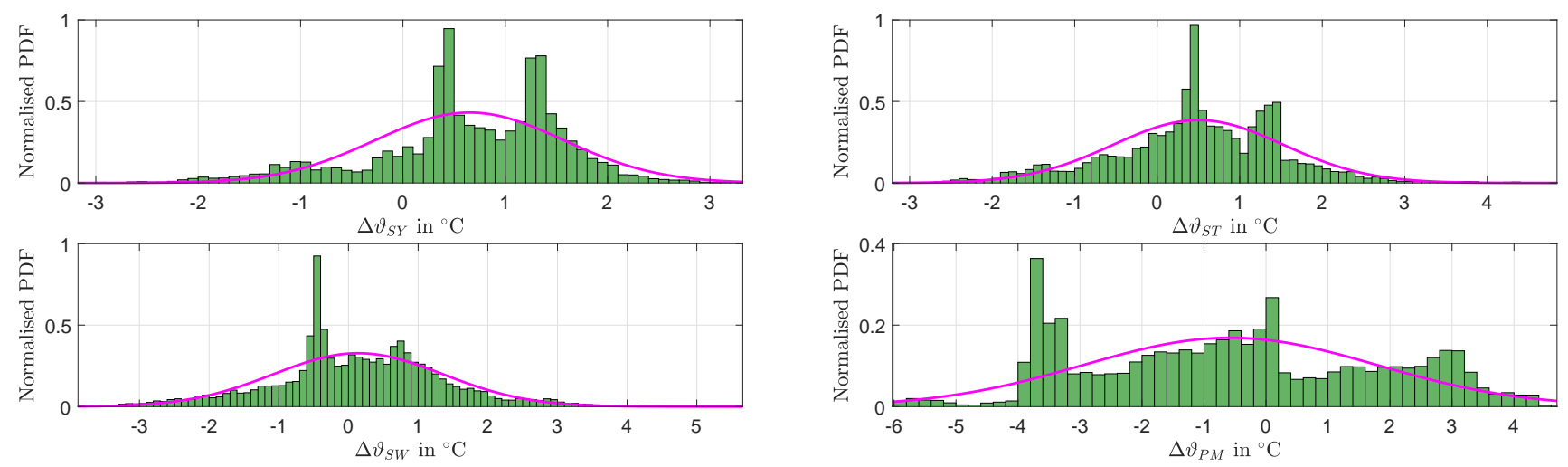

Fig. 9: Histogram of estimation error. (— Normalised probability density function (pdf), —Gaussian distribution), Profile 2 

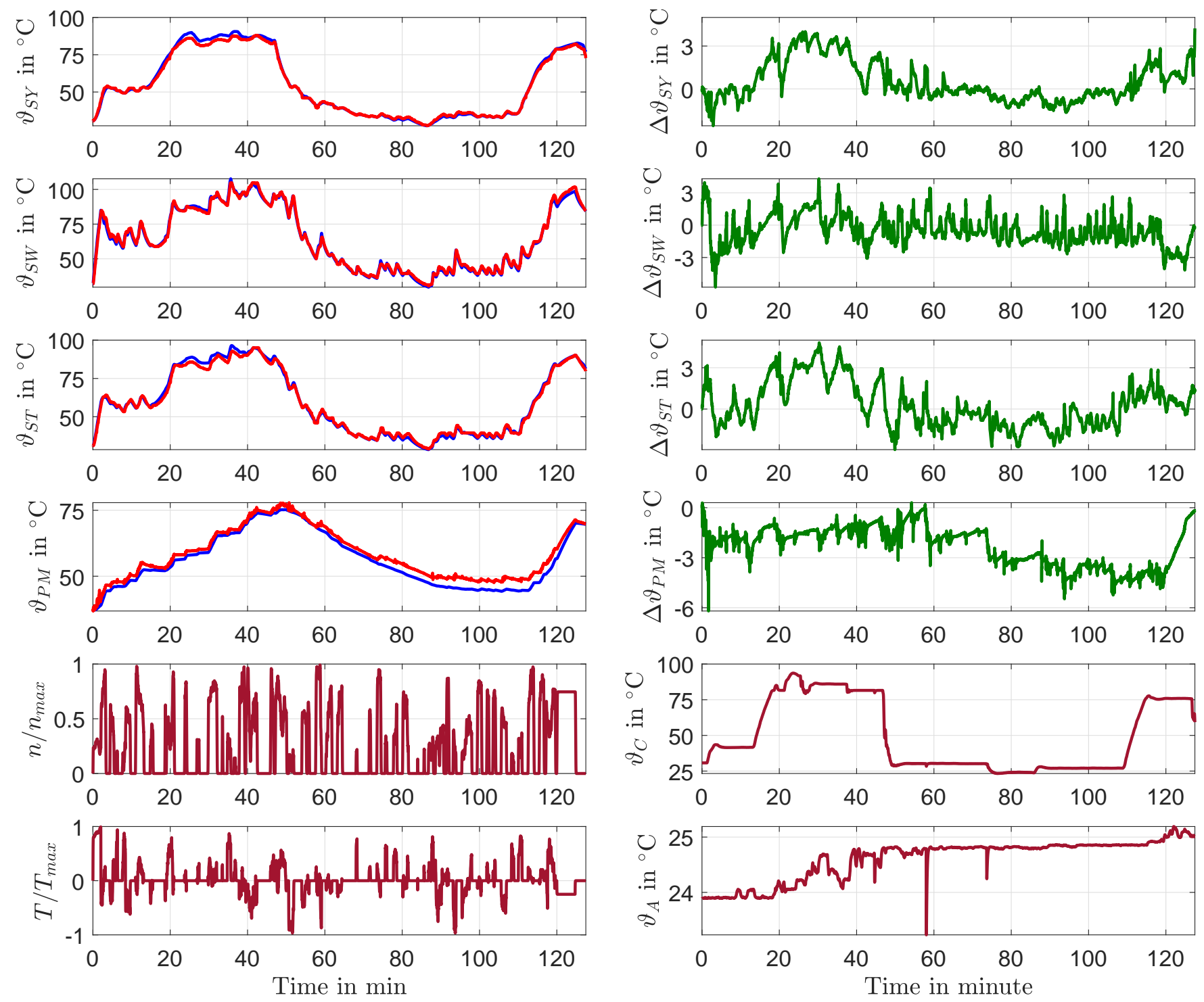

Fig. 10: LPTN validation with unseen profile. (—measured temperature,—estimated temperature, —error temperatures- unseen cross-validation profile), Profile 3
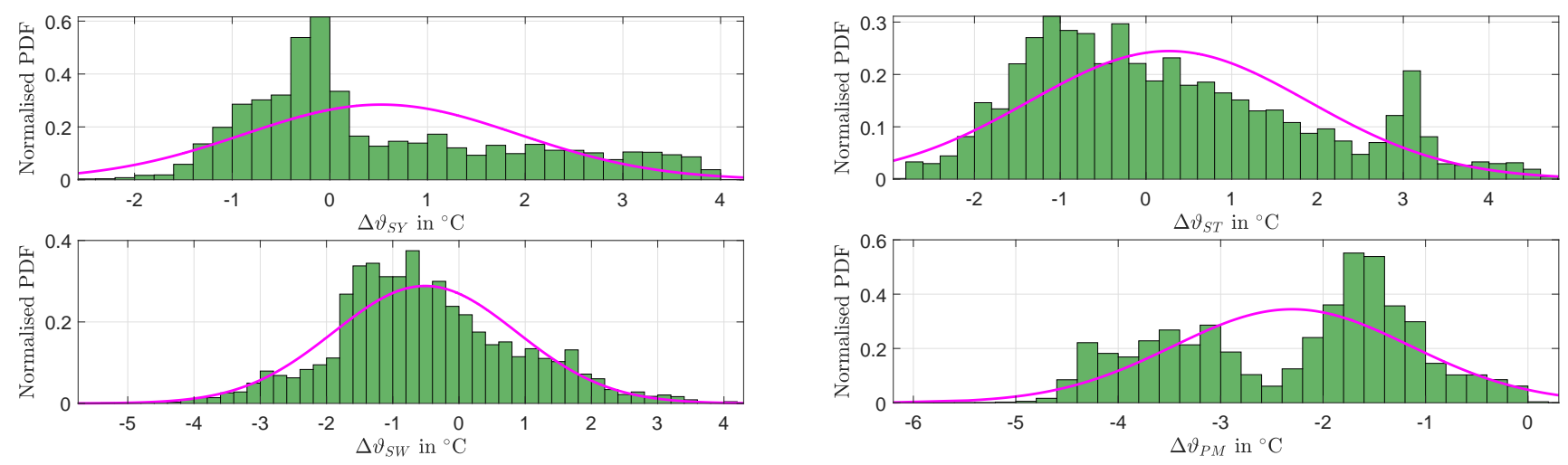

Fig. 11: Histogram of estimation error. (— Empirical distribution histogram, —-fitted Gaussian distribution), Profile 3 